Check for updates

Cite this: RSC Adv., 2018, 8, 14694

Received 3rd January 2018

Accepted 11th April 2018

DOI: $10.1039 / c 8 \mathrm{ra00047f}$

rsc.li/rsc-advances

\section{Magnetic interactions and in vitro study of biocompatible hydrocaffeic acid-stabilized Fe-Pt clusters as MRI contrast agents $\uparrow$}

N. Kostevšek, (DD *a S. Hudoklin, ${ }^{\text {b }}$ M. E. Kreft, (iD ${ }^{b}$ I. Serša, (DD ${ }^{c}$ A. Sepe, ${ }^{c}$ Z. Jagličić, (DD d J. Vidmar, (D) J. Ščančar, (D) S. Šturm, (D) af S. Kobe (iD af and K. Žužek Rožman (iD af

A detailed magnetic study of separated Fe-Pt NPs and Fe-Pt clusters was performed to predict their optimal size and morphology for the maximum saturation magnetization, a factor that is known to influence the performance of a magnetic-resonance-imaging (MRI) contrast agent. Excellent stability and biocompatibility of the nanoparticle suspension was achieved using a novel coating based on hydrocaffeic acid (HCA), which was confirmed with a detailed Fourier-transform infrared spectroscopy (FTIR) study. An in vitro study on a human-bladder papillary urothelial neoplasm RT4 cell line confirmed that HCA-Fe-Pt nanoparticles showed no cytotoxicity, even at a very high concentration (550 $\mu \mathrm{g} \mathrm{Fe-Pt}$ per $\mathrm{mL}$ ), with no delayed cytotoxic effect being detected. This indicates that the HCA coating provides excellent biocompatibility of the nanoparticles, which is a prerequisite for the material to be used as a safe contrast agent for MRI. The cellular uptake and internalization mechanism were studied using ICPMS and TEM analyses. Furthermore, it was shown that even a very low concentration of $\mathrm{Fe}-\mathrm{Pt}$ nanoparticles $\left(<10 \mu \mathrm{g} \mathrm{mL}^{-1}\right)$ in the cells is enough to decrease the $T_{2}$ relaxation times by $70 \%$. In terms of the MRI imaging, this means a large improvement in the contrast, even at a low nanoparticle concentration and an easier visualization of the tissues containing nanoparticles, proving that HCAcoated Fe-Pt nanoparticles have the potential to be used as an efficient and safe MRI contrast agent.

\section{Introduction}

The magnetic properties of the fcc (face-centred cubic) Fe-Pt system include a high Curie temperature and a high bulk saturation magnetization (i.e., about $1140 \mathrm{emu} \mathrm{cm}^{-3}=75 \mathrm{emu} \mathrm{g}^{-1}$ $\left.\left(\rho=14 \mathrm{~kg} \mathrm{~m}^{-3}\right)\right),{ }^{1-3}$ which along with its good chemical stability ${ }^{2,4}$ promises the possibility of diverse implementations in biomedicine, e.g., use as a contrast agent in MRI, separation,

${ }^{a}$ Department for Nanostructured Materials, Jožef Stefan Institute, Jamova 39, Ljubljana, Slovenia. E-mail: nina.kostevsek@ijs.si

${ }^{b}$ Institute of Cell Biology, Faculty of Medicine, University of Ljubljana, Vrazov trg 2, Ljubljana, Slovenia

${ }^{c}$ Department for Condensed Matter Physics, Jožef Stefan Institute, Jamova 39, Ljubljana, Slovenia

${ }^{d}$ Institute of Mathematics, Physics and Mechanics \& Faculty of Engineering and Geodesy, University of Ljubljana, Jadranska 19, 1000 Ljubljana, Slovenia

${ }^{e}$ Department for Environmental Sciences, Jožef Stefan Institute, Jamova 39, Ljubljana, Slovenia

Jožef Stefan International Postgraduate School, Jamova 39, Ljubljana, Slovenia

$\dagger$ Electronic supplementary information (ESI) available: Details about $D_{\mathrm{SPL}}$ calculation for fcc Fe-Pt NPs, TEM images of separated Fe-Pt NPs and Fe-Pt clusters with corresponding magnetic measurements, zeta-potential measurements of aqueous suspensions of the separated Fe-Pt NPs and Fe-Pt clusters after ligand exchange with HCA, FTIR spectra for pure OA, OLA and HCA ligands, and OA, OLA-coated Fe-Pt NPs with description of the assigned peaks. See DOI: $10.1039 / \mathrm{c} 8 \mathrm{ra00047f}$ immunoassays, cell targeting, drug delivery, hyperthermia and magnetic particle imaging. ${ }^{5}$ The value of the material's magnetization has a strong influence on the performance of the nanoparticles (NPs) in all of the above-mentioned applications. The $m_{\mathrm{s}}$ of Fe-Pt NPs can be increased by increasing their size; ${ }^{6}$ however, in this direction we are limited by the superparamagnetic size limit. This limitation can be bypassed by the formation of controlled clusters of smaller superparamagnetic Fe-Pt NPs. ${ }^{7}$ This approach was successfully applied in our previous study, where the Fe-Pt NPs' magnetization, which equalled 8 emu $\mathrm{g}^{-1}$, was increased to $19.5 \mathrm{emu}^{-1}$ for Fe-Pt clusters by changing the ratio and volume of the added surfactants (oleic acid and oleylamine), while keeping the Fe-Pt NPs in the superparamagnetic regime. In this study we have investigated the mechanism behind the increase in the $m_{\mathrm{s}}$ in the case of Fe-Pt clusters and thereby tried to answer the question "what is the maximum $m_{\mathrm{s}}$ that can be achieved in the superparamagnetic regime for Fe-Pt NPs". To do this, the magnetic interactions between the Fe-Pt NPs were evaluated using temperature-dependent field-cooled and zerofield-cooled (FC/ZFC) magnetic susceptibility curves.

There are only a limited number of studies that can be found in the literature referring to testing the cytotoxicity of Fe-Pt NPs. ${ }^{8-17}$ In all these examples only three different coatings were used, mostly cysteamine, followed by cysteine and three examples of PEG-based coatings. This demonstrates that Fe-Pt NPs 
are promising candidates for several biomedical applications, but there is a clear gap in the development of new biocompatible NPs coatings, which would shift the concentration range where NPs show no cytotoxic effect to the highest possible values. Literature reports on Fe oxide NPs have shown that the dopamine provides a strong coordination to the NP surface, ${ }^{\mathbf{1 8 , 1 9}}$ while the carboxylic group is responsible for the high water solubility and suspension stability across the wide $\mathrm{pH}$ range. ${ }^{18}$ We have demonstrated in the previous work on the example of the zwitterionic dopamine sulphonate (ZDS) ligand that dopamine-based ligands are good candidates for the functionalization and stabilization of Fe-Pt NPs. ${ }^{6}$ As the continuation of the search for a simple-to-synthesize, efficient and biocompatible ligand, we propose in this study a new ligand from the family of dopamine-based ligands, i.e., hydrocaffeic acid (HCA). HCA was selected as a ligand because of its natural origin. Polyphenol-rich foods, such as vegetables and fruits, contain HCA. ${ }^{20,21}$ Moreover, HCA is a metabolite of caffeic acid and has potent antioxidant properties, even more effective than the caffeic acid. To the best of our knowledge, this study is a first report about functionalization of Fe-Pt NPs with HCA ligand.

A change in the environment can drastically influence the NPs' stability and, consequently, their performance. Therefore, in order to better understand the behaviour of the NPs in the cellular environment and their influence on the cell viability, an in vitro study on the cancer urothelial RT4 cell line was performed. First, possible cytotoxicity of HCA-functionalized Fe-Pt NPs was evaluated over a broad concentration range (10-550 $\mu \mathrm{g}$ $\mathrm{mL}^{-1}$ of Fe-Pt NPs). Secondly, the cell viability was followed up to one week after the NPs' removal to asses any possible delayed cytotoxic effect. Then, the process of the NPs' internalization and the mechanism of the cellular uptake was determined. Finally, to test the performance of the Fe-Pt NPs as the contrast agents, in vitro MRI measurements were performed and the effect of the NPs' presence in the cells on the shortening of the relaxation times was evaluated.

Briefly, this work represents the entire workflow, from the optimization of the magnetic performance by forming clusters of superparamagnetic NPs, an investigation of the magnetic interactions responsible for the increase in the $m_{\mathrm{s}}$, via the successful functionalization of NPs with biocompatible HCA ligand, which was supported with a full characterization, to an evaluation of the possible cytotoxicity and a demonstration of their potential for use as a safe contrast agent in MRI.

\section{Experimental}

\subsection{Materials for the preparation of HCA-Fe-Pt NPs}

For the synthesis of the Fe-Pt NPs, platinum acetylacetonate $\mathrm{Pt}(\text { acac) })_{2}$ (Merck), iron acetylacetonate $\mathrm{Fe}(\text { acac) })_{3}(>99.9 \%$ SigmaAldrich), benzyl ether (>98\%, Merck), oleic acid (OA, >99\%, Sigma-Aldrich), oleylamine (OLA, 70\%, Sigma-Aldrich), 1,2hexadecanediol (90\%, Sigma-Aldrich), hexane (>95\%, Sigma Aldrich) and ethanol absolute anhydrous ( $>99.9 \%$, Carlo Erba Reagents) were used. For the ligand-exchange reaction and the functionalization of the Fe-Pt surface with the HCA ligand the following reagents were used: tetrahydrofuran (THF, anhydrous, $>99.9 \%$, Sigma Aldrich), hydrocaffeic acid (HCA, 3(3,4-dihydroxyphenyl)propionic acid, >98\%, Sigma Aldrich) and $\mathrm{NaOH}$ (anhydrous, $>98 \%$, Sigma Aldrich).

Synthesis of Fe-Pt NPs. The Fe-Pt NPs were prepared as described in our previous article. ${ }^{6}$ Briefly, at room temperature, $0.5 \mathrm{mM}$ of $\mathrm{Pt}(\mathrm{acac})_{2}$ and $1 \mathrm{mM}$ of $\mathrm{Fe}(\mathrm{acac})_{3}$ were added into a round-bottom flask containing $20 \mathrm{~mL}$ of benzyl ether. Then $4 \mathrm{~mL}$ of oleic acid and $4 \mathrm{~mL}$ of oleylamine were added. Before heating to $260{ }^{\circ} \mathrm{C}$ for $30 \mathrm{~min}$ the reducing agent 1,2-hexadecanediol $(2.3 \mathrm{mmol})$ was added at $160{ }^{\circ} \mathrm{C}$. The black product was precipitated by adding absolute ethanol and separated by centrifugation (6000 $\mathrm{rpm} / 10 \mathrm{~min}$ ) and then re-dispersed in hexane. For the preparation of Fe-Pt clusters the oleic-acid-tooleylamine ratio was changed, i.e., $2 \mathrm{~mL}$ of oleic acid and $4 \mathrm{~mL}$ of oleylamine, while all the other parameters were kept the same as in the synthesis of separated Fe-Pt NPs.

Ligand-exchange reaction. The as-prepared hydrophobic $\mathrm{Fe}-$ Pt NPs $(20 \mathrm{mg})$ were dispersed in $1 \mathrm{~mL}$ of THF. The solution of ligand was prepared by dissolving $50 \mathrm{mg}$ of HCA in $5 \mathrm{~mL}$ of THF. Hydrophobic NPs were added dropwise to the solution of the ligand and the reaction mixture was then stirred at $50{ }^{\circ} \mathrm{C}$ for $3 \mathrm{~h}$ to complete the reaction. Upon cooling the reaction mixture to room temperature, $0.5 \mathrm{~mL}$ of $0.5 \mathrm{M} \mathrm{NaOH}$ was added to precipitate the NPs, which were collected by centrifugation and re-dispersed in water.

\subsection{Methods}

For the synthesis of the Fe-Pt NPs, a hemispherical heating mantle (model WiseTherm WHM 12112 from Witeg Labortechnik $\mathrm{GmbH}$ ) connected to a temperature controller (J-KEM, model 310) with a J-type Teflon thermocouple was used. The samples were characterized using a (scanning) transmission electron microscope (TEM Jeol JEM-2010F) equipped with energy-dispersive X-ray spectroscopy (EDXS). Low-temperature magnetic measurements were performed on a Quantum Design MPMS-XL-5 SQUID magnetometer. With the thermogravimetric analyses (TG analyser NETZSCH STA 449 C/6/G Jupiter) the amount of organic matter in the sample was determined to be $30 \%$. The magnetization values are reported for the mass of Fe-Pt in the sample after the subtraction of the organic content. Fourier-transform infrared spectroscopy (FTIR) measurements were performed using a Spectrum 400 spectrometer (Perkin Elmer, USA). The spectra were recorded on dried samples in the wavenumber range 4000-650 $\mathrm{cm}^{-1}$.

ICP-MS analysis. The total concentrations of $\mathrm{Fe}$ and $\mathrm{Pt}$ in the analysed samples were determined by mass spectrometry with inductively coupled plasma (ICP-MS, Agilent 7700 ICP-MS instrument, Agilent Technologies, Tokyo, Japan). Stock solutions of Pt $(1000 \mu \mathrm{g}$ Pt per $\mathrm{mL}$ in $8 \% \mathrm{HCl})$ and $\mathrm{Fe}(1000 \mu \mathrm{g} \mathrm{Fe}$ per $\mathrm{mL}$ in $2-3 \% \mathrm{HNO}_{3}$ ), all obtained from Merck (Darmstadt, Germany), were diluted with water for the preparation of fresh calibration standard solutions. For the determination of Fe and Pt in an aqueous suspension of Fe-Pt NPs, to a $0.5 \mathrm{~mL}$ of NPs suspension $1.5 \mathrm{~mL}$ of hydrochloric acid (30\% $\mathrm{HCl}$, suprapure) and $0.5 \mathrm{~mL}$ of nitric acid (65\% $\mathrm{HNO}_{3}$, suprapure) were added. The sample was heated on a hotplate (C-MAG HP10, IKA, 
Germany) at $100{ }^{\circ} \mathrm{C}$ for $10 \mathrm{~min}$ until the colour of the solution turned yellow. After the digestion, the sample was filled with MilliQ water to a final volume of $10 \mathrm{~mL}$ and appropriately diluted prior to the ICP-MS measurements. Digestion was performed in duplicate. For the determination of the $\mathrm{Fe}$ and $\mathrm{Pt}$ concentrations in the cells' suspensions, $2 \mathrm{~mL}$ of sample was digested with $0.75 \mathrm{~mL}$ of $\mathrm{HCl}, 0.5 \mathrm{~mL}$ of $\mathrm{HNO}_{3}$ and $1.25 \mathrm{~mL}$ of hydrogen peroxide $\left(30 \% \mathrm{H}_{2} \mathrm{O}_{2}\right.$, suprapure $)$ and heated at $90{ }^{\circ} \mathrm{C}$ overnight in an oven (Binder $\mathrm{GmbH}$, Tuttlingen, Germany). After the digestion, the sample was filled up with MilliQ water to a final volume of $10 \mathrm{~mL}$ and appropriately diluted prior to the ICP-MS measurements. All the dilutions of the samples were made with ultrapure water $(18.2 \mathrm{M} \Omega \mathrm{cm})$ obtained from a Direct-Q 5 Ultrapure water system (Merck Millipore, Milford, MA, USA). Nitric acid $\left(65 \% \mathrm{HNO}_{3}\right)$, hydrochloric acid $(30 \% \mathrm{HCl})$ and hydrogen peroxide $\left(30 \% \mathrm{H}_{2} \mathrm{O}_{2}\right)$ were obtained from Merck Millipore, Milford, MA, USA.

\subsection{In vitro experiments, cell viability and TEM}

Cell line of human cancer urothelial cells, derived from papillary neoplasm, was established as described previously. ${ }^{22}$ Human-bladder papillary urothelial neoplasm (RT4) cells were seeded with a density of $5 \times 10^{4}$ cells per $\mathrm{cm}^{2}$ (TPP, Trasadingen, Switzerland) and grown in A-DMEM/F12 (1 : 1) (Gibco), 5\% fetal bovine serum (FBS; Gibco) (FBS), 4 mM GlutaMAX (Gibco), $100 \mathrm{U} \mathrm{mL}^{-1}$ penicillin, and $100 \mu \mathrm{g} \mathrm{mL}^{-1}$ streptomycin and were maintained at $37{ }^{\circ} \mathrm{C}$ in a humidified $5 \% \mathrm{CO}_{2}$ atmosphere for 1 week before the experiments. All the HCA-Fe-Pt NP incubation experiments were performed in the same culture medium as used to establish the urothelial RT4 cell model.

Cell viability. A Trypan-blue viability assay was used to determine the viability of the RT4 cells after HCA-Fe-Pt NP exposure. The cells were grown in 6-well plates and then incubated with different concentrations of NPs (10, 50, 100, 250 and $550 \mu \mathrm{g}$ Fe-Pt per $\mathrm{mL}$ ) for $24 \mathrm{~h}$. After the incubation the cells were washed to remove the non-internalized NPs, trypsinized until all the cells were detached and following the manufacturer's instructions immediately stained with Trypan-blue dye, which labels only dead cells. The live and dead cells were than counted manually under an inverted light microscope (Leica). The percentage of viable cells (\% viability) in a given sample was determined as the ratio between the number of viable cells and all the cells in the sample. In addition, cell viabilities were also calculated 7 days after the incubation with the NPs. The cell viabilities were analyzed in two independent experiments, each with at least four technical repeats.

Transmission electron microscopy. The RT4 cells were incubated with $100 \mu \mathrm{g} \mathrm{mL} \mathrm{m}^{-1}$ HCA-Fe-Pt NPs for 1 or $12 \mathrm{~h}$ at $37{ }^{\circ} \mathrm{C}$, washed to remove the non-internalized NPs and then fixed or cultured for an additional $24 \mathrm{~h}$. The samples were fixed with a mixture of $3 \%$ paraformaldehyde and $3 \%$ glutaraldehyde in $0.1 \mathrm{M}$ cacodylate buffer overnight at $4{ }^{\circ} \mathrm{C}$ and subsequently in $2 \%$ osmium tetraoxide for $1 \mathrm{~h}$ at room temperature. The samples were stained en bloc with $2 \%$ uranyl acetate for $1 \mathrm{~h}$, dehydrated in a graded series of ethanol solutions and embedded in Epon 812 resin (Serva Electrophoresis,
Heidelberg, Germany). Semi-thin $(1 \mu \mathrm{m})$ and ultra-thin (65 $\mathrm{nm})$ sections were cut using an Ultracut UCT microtome (Leica, Austria). The semi-thin sections were contrasted with toluidine blue and examined under a light microscope to determine the positions of the cells. Ultra-thin sections were examined with a Philips CM100 TEM.

In vitro MRI. Relaxation-time measurements were made on an NMR/MRI system consisting of a 9.4-T superconducting magnet (Jastec, Kobe, Japan) and a Redstone NMR spectrometer (Tecmag, Houston TX, USA). The $T_{1}$ relaxation times were measured using an inversion-recovery sequence with 16 different inversion times, ranging from $100 \mu$ s to $10 \mathrm{~s}$, while the $T_{2}$ relaxation times were measured using the Carr Purcell Meiboom Gill (CPMG) sequence with multiple spin-echoes. The $T_{1}$ and $T_{2}$ relaxation times were calculated from the best fits between the measurements and the corresponding model for either $T_{2}$ relaxation (exponential dependency of the echo-signal on the echo number) or $T_{1}$ relaxation (dependency of the inversion recovery signal on the inversion time). The calculations were performed using the Origin program (OriginLab Corporation, Northampton MA, USA). The cells were incubated with different concentrations of HCA-Fe-Pt NPs (0, 10, 50 and $100 \mu \mathrm{g} \mathrm{mL} \mathrm{m}^{-1}$ ) for $12 \mathrm{~h}$. After the incubation the cell-culture media containing the NPs was removed, the cells were washed to remove all NPs that were not taken up and then densified into a pellet with centrifugation. Suspensions of the cells were centrifuged in tubes for the relaxivity measurements (height $70 \mathrm{~mm}$ and diameter $8 \mathrm{~mm}$ ) at $1300 \mathrm{rpm}$ for 5 minutes. The supernatant was removed and an as-prepared pellet of cells was used in the measurements.

\section{Results and discussion}

\subsection{Synthesis and magnetic characterization}

Separated Fe-Pt NPs and Fe-Pt clusters were prepared according to the optimized procedure described in the literature ${ }^{6}$ by changing the ratio between the two surfactants, oleic acid (OA) and oleylamine (OLA), that are used in the synthesis. TEM images of the separated Fe-Pt NPs and Fe-Pt clusters are shown in Fig. S-1a and S-1b in the ESI, $\dagger$ respectively. The structure of the clusters was proven using high-resolution TEM analysis in our previous study. ${ }^{6}$ The average size (defined as the average diameter) of the separated Fe-Pt NPs measured on the basis of 30 individual particles was found to be $7 \pm 1 \mathrm{~nm}$. In the case of the Fe-Pt clusters the average size was estimated by measuring the average diameter of the body, and the average particle size was determined to be $20 \pm 3 \mathrm{~nm}$. The elemental composition determined from the obtained EDXS data was $\mathrm{Fe}_{25 \pm 1} \mathrm{Pt}_{75 \pm 1}$ and $\mathrm{Fe}_{30 \pm 1} \mathrm{Pt}_{70 \pm 1}$ for the separated Fe-Pt NPs and Fe-Pt clusters, respectively. A slightly higher content of $\mathrm{Fe}$ in the case of the $\mathrm{Fe}-$ Pt clusters can be attributed to the lower content of OA during the synthesis, since it was suggested that OA is a coordinative ligand for the Fe atoms, and OLA is said to coordinate the Pt intermediates. ${ }^{23}$ Therefore, a smaller amount of OA would result in fewer coordinated Fe metal intermediates in the reaction mixture and hence NPs with a slightly higher Fe content. The step from smaller separated Fe-Pt NPs to the larger, Fe-Pt 
clusters $(>20 \mathrm{~nm})$ leads to an increase in the magnetization $m_{(1.5 \mathrm{~T})}$ from 8 to $19.5 \mathrm{emu} \mathrm{g}^{-1}$ (Fig. S-1c $\dagger$ ), without exceeding the superparamagnetic limit. In order to gain an insight into the magnetic interactions acting between the Fe-Pt NPs, which can be used to explain the mechanism behind the increase in the $m_{\mathrm{s}}$ in the case of $\mathrm{Fe}-\mathrm{Pt}$ clusters, the temperature-dependent fieldcooled and zero-field-cooled (FC/ZFC) magnetic susceptibility curves were recorded and are shown in Fig. 1a. The blocking temperatures $\left(T_{\mathrm{b}}\right)$ for the separated $\mathrm{Fe}-\mathrm{Pt} \mathrm{NPs}$ and Fe-Pt clusters were determined to be $36 \mathrm{~K}$ and $121 \mathrm{~K}$, respectively. This is in good agreement with the Néel relaxation theory, where larger particles have a higher $T_{\mathrm{b}}$. The broader peak in the case of the $\mathrm{Fe}-\mathrm{Pt}$ clusters indicates a broader size distribution, which is consistent with the results obtained from the TEM analysis. Moreover, $T_{\mathrm{b}}$ can be shifted towards higher temperature due to the presence of the magnetic dipole interactions.

The spin structure of the NPs can be affected by the interparticle interactions, which are mainly long-range dipoledipole interactions and the exchange interactions through the surface of the particle. If the magnetic susceptibility (FC curve) becomes temperature independent at $T \ll T_{\mathrm{b}}$ and reaches saturation, this indicates the presence of inter-particle dipole interactions. It is clear from the graph in Fig. 1a that for both samples the susceptibility of the FC curves in the range $T \ll T_{\mathrm{b}}$ increases with the decreasing temperature. Even though
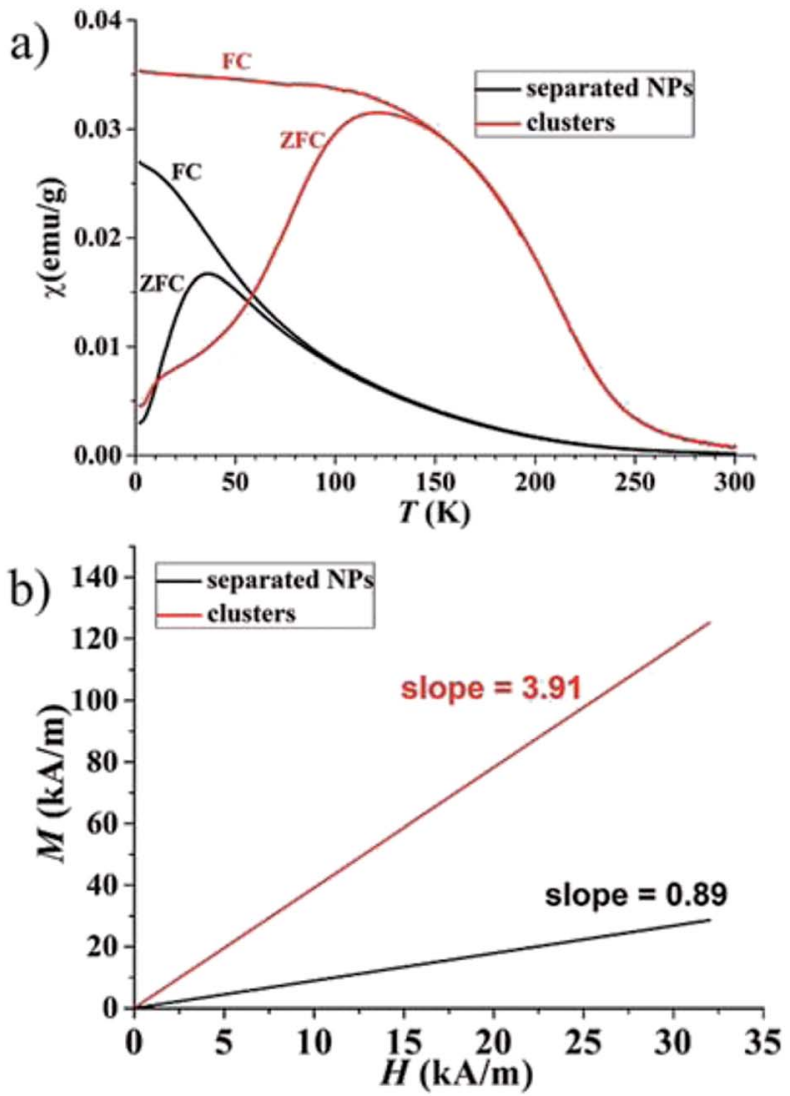

Fig. 1 (a) Temperature-dependent field-cooled and zero-fieldcooled (FC/ZFC) magnetic susceptibility curves for separated Fe-Pt NPs and Fe-Pt clusters and (b) initial magnetization at low $\mathrm{H}(0-32 \mathrm{kA}$ $\mathrm{m}^{-1}$ ) measured at $300 \mathrm{~K}$. complete saturation is not reached, it can be inferred from the FC curves that the Fe-Pt NPs in dry form are weakly interacting. The Fe-Pt clusters show a less steep curve in that temperature range, which can be attributed to the stronger dipole interactions, as in the case of the separated Fe-Pt NPs. The larger dipole interactions in the case of the larger NPs might arise due to the higher saturation magnetization. ${ }^{24}$ Similar behaviour was shown for the case of the 3- and $9 \mathrm{~nm}$-sized fcc Fe-Pt NPs, where both samples have non-negligible dipole interactions, the effect being smaller in the smaller NPs. ${ }^{24}$ It must be pointed out that the samples for the ZFC/FC measurements were in a dry form with the inter-particle distance being reduced; therefore, significant dipole interactions at lower temperature could be expected. If, however, the magnetic dipolar interactions would also be significant at room temperature, they would compromise the superparamagnetic properties and the colloidal stability of the suspension, which was not the case in our study. We additionally presume that in the case of separated Fe-Pt NPs in the suspensions the direct exchange interactions between the individual NPs might be neglected due to the surfactant coating, which prevents their direct contact. ${ }^{25}$ However, in clusters the exchange interactions, i.e., the intra-particle collective behaviour, can be present, which leads to an enhancement in the effective magnetic moment of the clusters, as was already observed by Lartigue $e t ~ a l .{ }^{26}$ in Fe-oxide clusters. The clustering of the NPs would have an influence on the effective magnetic moment of the NP ( $\left.\mu_{\text {eff }}\right)$, which can be determined using the following procedure. From the magnetic hysteresis measurements (Fig. S-1c†), the initial susceptibility of the samples $\left(\chi_{0}\right)$ can be calculated using the slope of the $M\left(\mathrm{kA} \mathrm{m}^{-1}\right)$ vs. $H\left(\mathrm{kA} \mathrm{m}^{-1}\right)$ curve at low $H$. The mass magnetization $\left(\mathrm{emu} \mathrm{g}^{-1}\right)$ was converted to volumetric magnetization (emu $\mathrm{cm}^{-3}$ ) by assuming a density of Fe-Pt NPs equal to $14 \mathrm{~g} \mathrm{~cm}^{-3}$. For the calculation purposes in this case $M(\mathrm{emu}$ $\left.\mathrm{cm}^{-3}\right)$ and $H(T)$ were converted into SI units $\left(\mathrm{kA} \mathrm{m}^{-1}\right) . M-H$ curve at low $H\left(0-32 \mathrm{kA} \mathrm{m}^{-1}\right)$ for the separated Fe-Pt NPs and Fe-Pt clusters is shown in Fig. 1b. The initial susceptibility $\left(\chi_{0}\right)$ was found to be 0.89 and 3.93 for the separated Fe-Pt NPs and $\mathrm{Fe}-\mathrm{Pt}$ clusters, respectively. Furthermore, by using the relation

$$
\chi_{0}=\mu_{0} \frac{1}{V_{\mathrm{tot}}} \frac{\mu_{\mathrm{eff}}^{2}}{3 k_{\mathrm{b}} T},
$$

the effective magnetic moment for the nanostructure ( $\mu_{\text {eff }}$, can be calculated, where $V_{\text {tot }}$ is the total volume of a NP, $k_{\mathrm{b}}$ is the Boltzmann constant $\left(1.38 \times 10^{-23} \mathrm{~J} \mathrm{~K}^{-1}\right), T$ is the temperature (K) and $\mu_{0}$ is the permeability of a vacuum $\left(4 \pi \times 10^{-7} \mathrm{~N}\right.$ $\left.\left.\mathrm{A}^{-2}\right)\right)_{.}^{27,28}$ Reorganization of eqn (1) gives an expression for the direct calculation of $\mu_{\text {eff: }}$

$$
\mu_{\text {eff }}^{2}=\frac{V_{\text {tot }} \chi_{0} 3 k_{\mathrm{b}} T}{\mu_{0}},
$$

The effective magnetic moment of the NPs $\left(\mu_{\text {eff }}\right)$ was then calculated by using eqn (2). The volume of the Fe-Pt NPs was estimated to be $V_{\text {(separated) }}$ and $V_{\text {(clusters) }} 1.13 \times 10^{-25} \mathrm{~m}^{3}$ and $1.76 \times 10^{-24} \mathrm{~m}^{3}$, respectively. The calculated effective magnetic moments are $\mu_{\text {eff-(separated) }}=3 \times 10^{-20} \mathrm{~A} \mathrm{~m}^{2}$ and $\mu_{\text {eff-(clusters) }}=$ 
$26 \times 10^{-20} \mathrm{~A} \mathrm{~m}^{2}$. From the above calculations it can be seen that the Fe-Pt clusters possess a higher effective magnetic moment than the separated ones. Moreover, if the particles in the clusters structure are assumed to have the same magnetic moment (magnetic moment of the particle, $\mu_{\mathrm{p}}$ ) and are magnetically non-interacting, we would expect that the effective magnetic moment of the cluster $\left(\mu_{\text {eff }}\right)$ would follow the statistical relation for randomly oriented independent (non-interacting) particle magnetic moments $\left(\mu_{\mathrm{p}}\right)$ according to the relation: ${ }^{27}$

$$
\mu_{\text {eff }}=\sqrt{N} \mu_{\mathrm{p}}
$$

where $N$ is the number of particles in the cluster. If we assume that the average number of particles in the cluster is 8 , the

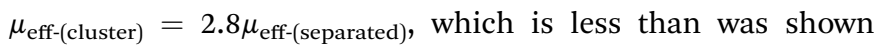

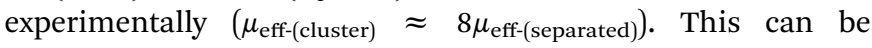
attributed to the collective magnetic behaviour of the $\mathrm{Fe}-\mathrm{Pt}$ particles $^{26}$ and/or to the slight increase in the particle size, which was confirmed by TEM.

Furthermore, surface effects can also significantly influence the magnetic properties of the NPs. In the case of clusters, the surface-to-volume ratio is reduced due to coalescence of the individual particles, which could also contribute to the increase of the magnetization. According to eqn (4) the saturation magnetization of NPs $\left(m_{\mathrm{s}}\right)$ is proportional to the NPs' size:

$$
m_{s}=M_{s}[(r-d) / r]^{3} \text {, }
$$

where $r$ is the radius of the NP and $d$ is the thickness of the disordered surface spin layer. Eqn (4) shows that the maximum magnetization can be obtained when the disordered surface spin layer disappears. The theoretically calculated $m_{\mathrm{s}}$ for separated Fe-Pt NPs obtained from eqn (4) are shown in Fig. 2 (black line), where $r=1.6-7.5 \mathrm{~nm}, d=1.5 \mathrm{~nm}$ and $m_{\mathrm{s}}=75 \mathrm{emu} \mathrm{g}^{-1}$ were used. The experimental $m_{\mathrm{s}}$ values $\left(m_{\mathrm{s}}=1.5-14 \mathrm{emu} \mathrm{g}^{-1}\right)$ for the separated Fe-Pt NPs in the range $r=1.6-4 \mathrm{~nm}$ were taken from our previous study ${ }^{6}$ and are plotted in a graph

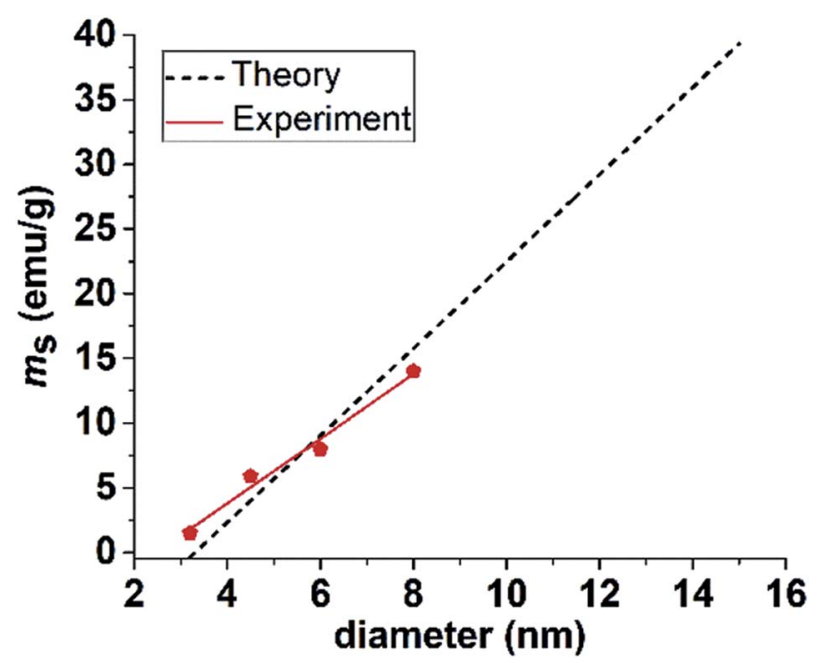

Fig. 2 Graph indicating theoretically calculated and experimentally obtained saturation magnetization for separated Fe-Pt NPs with different diameters. shown in Fig. 2 (red line). Combining all these data revealed a good match between theory and experiment. The Fe-Pt clusters have $m_{\mathrm{s}}=19.5 \mathrm{emu} \mathrm{g}^{-1}$. Plotting this value on the graph in Fig. 2, a theoretical NP with a diameter of $9.7 \mathrm{~nm}$ is obtained. This indicates that the cluster magnetically behaves as a separated particle with a size of $9.7 \mathrm{~nm}$. The TEM analysis of the FePt clusters showed that the size of the individual particles is in the range $8 \pm 1 \mathrm{~nm}$, which is "slightly" less than it was calculated using the above equation. From this it could be assumed that the magnetic ordering due to the presence of the intraparticle exchange interactions increases the magnetic diameter of the particles. Therefore, we can conclude that the observed increment in the magnetization of the clusters has a basis in the reduction of their surface disorder (smaller surface-to-volume ratio) and/or in the magnetic exchange interactions between the individual particles.

As no reports about the superparamagnetic size limit $\left(D_{\mathrm{SPL}}\right)$ for fcc Fe-Pt can be found in the literature, we used an experimental $T_{\mathrm{b}}$ to calculate $D_{\mathrm{SPL}}$, which was found to be approximately $10 \mathrm{~nm}$. Details can be found in the ESI. $\dagger$ Based on the presented results we can conclude that the highest possible magnetization for our Fe-Pt system would be theoretically obtained by fabricating separated Fe-Pt NPs with a particle size just below $D_{\mathrm{SPL}}$ and combine them together into clusters, introducing the collective magnetic behaviour without crossing the SPL. For example, the calculated $m_{\mathrm{s}}$ for separated NPs with a size around SPL $(10 \mathrm{~nm})$ is $23 \mathrm{emu} \mathrm{g}^{-1}$. Therefore, due to the presence of the exchange interactions between the individual cores, combining $10 \mathrm{~nm}$-sized particles in clusters would lead to an even further increase in $m_{\mathrm{s}}$. However, this value is expected to still be much lower than the bulk saturation magnetization $\left(75 \mathrm{emu}^{-1}\right)$ that cannot be obtained in the superparamagnetic regime due to the prevalent surface effects. An experimental hint about the maximum size of the Fe-Pt clusters can be seen from the work of Green et al., ${ }^{7}$ where Fe-Pt clusters with a size above approximately $40 \mathrm{~nm}$ and $m_{\mathrm{s}}=29 \mathrm{emu} \mathrm{\textrm {g } ^ { - 1 }}$ already showed evidence of ferromagnetism at room temperature.

\subsection{Surface functionalization with HCA}

The as-synthesized hydrophobic Fe-Pt NPs were transferred to an aqueous phase by using the HCA ligand dissolved in tetrahydrofuran (THF), as schematically shown in Fig. 3a. Fig. S-2 in the $\mathrm{ESI} \uparrow$ evidently shows that after the ligand-exchange reaction the separated Fe-Pt NPs are negatively charged (from $-10 \mathrm{mV}$ at $\mathrm{pH}=2$ and $-50 \mathrm{mV}$ at $\mathrm{pH}=12$ ) across the whole $\mathrm{pH}$ range that

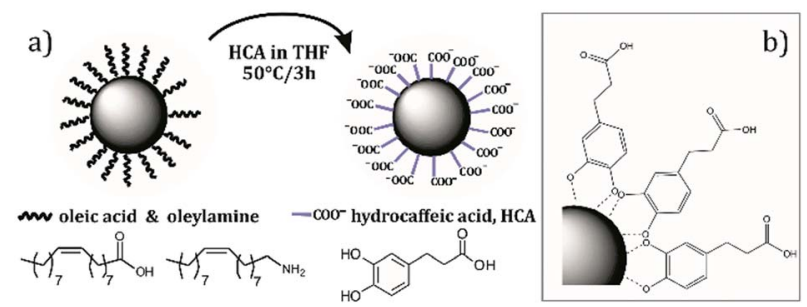

Fig. 3 (a) Schematic representation of a ligand-exchange reaction with HCA in THF and (b) chelate bonding of a HCA on Fe-Pt NPs. 
was used in the measurements. The negative zeta-potential is related to the deprotonation of the carboxylic group of the HCA ligand. High measured values of the zeta-potential enable a strong electrostatic repulsion between the NPs, which results in a persistent suspension stability for a period of several months. Higher relative zeta-potential values in the case of $\mathrm{Fe}-$ Pt clusters (from $-38 \mathrm{mV}$ at $\mathrm{pH}=2$ to $-70 \mathrm{mV}$ at $\mathrm{pH}=12$ ) can be attributed to a larger size of NPs where a larger surface allows for the attachment of more HCA molecules and, consequently, a higher surface charge can be obtained.

In order to examine the bonding between the different ligands (OLA, OA and HCA) and the NP's surface a detailed FTIR study was performed. Before the ligand-exchange reaction OLA and OA ligands can be found on the Fe-Pt NP surfaces. Individual FTIR spectra of the pure ligands, i.e., OA and OLA, with identified peaks are shown in Fig. S-3 and S-4 in the ESI, $\uparrow$ respectively. A detailed FTIR study of the OA and OLA bonding on the surface of Fe-Pt NPs can be found in the work of Shukla et al. ${ }^{29}$ FTIR spectra with a detailed description of assigned peaks for the as-synthesized OA- and OLA-stabilized Fe-Pt NPs together with the FTIR spectra of pure OA and OLA are shown in Fig. S-5 in the ESI. $\dagger$ A ligand-exchange reaction with HCA was performed to transfer the Fe-Pt NPs into the water phase. The FTIR spectrum of the pure HCA ligand was recorded (Fig. S-6 in the ESI $\dagger$ ) and a detailed explanation of the assigned peaks is given in the ESI. $\dagger$ From Fig. 4 it can be seen that the FTIR spectrum of the HCA-functionalized Fe-Pt NPs differs significantly from the FTIR spectra of the pure HCA ligand. The HCA ligand has two possible bonding sites with the NP's surface: the $\mathrm{COOH}$ group and the $\mathrm{OH}$ catechol groups; therefore, the major difference in the peak positions are expected to be related to the peaks correlated to those functional groups.

The first distinct change in the spectrum of the HCAfunctionalized Fe-Pt NPs occurs due the deprotonation of the carboxylic group. More precisely, peaks correlated to the $\nu(\mathrm{C}=\mathrm{O})=1670 \mathrm{~cm}^{-1}$ and $\nu(\mathrm{C}-\mathrm{O})=1290 \mathrm{~cm}^{-1}$ stretch mode of the protonated carboxylic group diminish and new peaks for the symmetric stretching at $\nu_{\text {asym }}(\mathrm{COO}-)=1556 \mathrm{~cm}^{-1}$ and asymmetric stretching of the carboxylate at $\nu_{\text {sym }}(\mathrm{COO}-)=1370$ and $1400 \mathrm{~cm}^{-1}$ appear. ${ }^{30}$ Splitting of the peaks often resulted from the formation of different carboxylate-metal inner-sphere

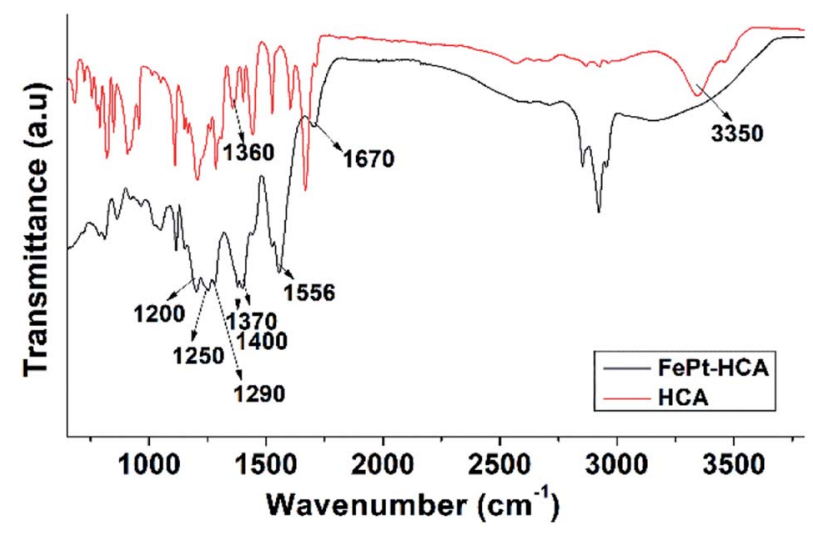

Fig. 4 FTIR spectra of pure HCA and HCA-functionalized Fe-Pt NPs. complexes. $^{31}$ The separation in wavenumber $\Delta \nu_{\text {(aysm-sym) }}$ for the asymmetric and symmetric stretching of carboxylate bands can be used to elucidate the bonding coordination. In general, $\Delta \nu$ values greater than about $200 \mathrm{~cm}^{-1}$ are thought to indicate monodentate binding, whereas $180-150 \mathrm{~cm}^{-1}$ indicates binuclear bidentate (bridging) complexes, and $<100 \mathrm{~cm}^{-1}$ indicates mononuclear bidentate binding (chelation). ${ }^{30}$ The separation in wavenumber $\Delta \nu_{\text {(aysm-sym) }}$ was determined to be 186 and $156 \mathrm{~cm}^{-1}$ for the first and second symmetric peaks, respectively. Therefore, it can be assumed that HCA ligand bonds to the NP's surface in the bidentate (bridging) form. The peak splitting might be attributed to the formation of HCA-Fe and HCA-Pt complexes at the Fe-Pt NP's surface. The presence of the peak that corresponds to the stretching mode $\left(\nu(\mathrm{C}-\mathrm{OH})=1200 \mathrm{~cm}^{-1}\right)$ indicates that the aryl oxygen stretching is not affected by the catechol adsorption on the NP's surface. Moreover, the peak at $\left(\nu(\mathrm{CO}-\mathrm{M})=1250 \mathrm{~cm}^{-1}\right)$ occurs when the catechol binds covalently to the metal as a catechol anion. In the case of the HCAfunctionalized Fe-Pt NPs the disappearance of both peaks, the stretching vibration of the $\mathrm{OH}$ groups (broad peak at 3200$3500 \mathrm{~cm}^{-1}$ ) and the bending vibrations of the catechol $\mathrm{OH}$ groups $\left(\nu(\mathrm{C}-\mathrm{OH})=1360 \mathrm{~cm}^{-1}\right)$ that are present in pure HCA, indicates bonding of the HCA to the Fe-Pt NPs surface with the catechol $\mathrm{OH}$ groups. ${ }^{32}$ From the obtained spectroscopic data it can be concluded that two types of binding structures for the HCA on the Fe-Pt NP's surface are possible, i.e., via carboxylic groups or catechol $\mathrm{OH}$ groups, which is in accordance with the literature data. ${ }^{33}$ The deprotonation of HCA is an indication of the bonding via the carboxylic groups. However, carboxylic groups on the outer surface do not bind to the Fe-Pt NP's surface, providing good suspension stability and a high negative zeta-potential. ${ }^{33}$ It is believed that the majority of the HCA molecules bind to the NP's surface via catechol groups, ${ }^{33}$ as schematically shown in Fig. $3 \mathrm{~b}$.

\subsection{In vitro studies}

3.3.1 Cytotoxicity of the HCA-Fe-Pt NPs. Due to their superior magnetic properties, Fe-Pt clusters were selected to be used in the in vitro studies and are subsequently referred to as HCA-Fe-Pt NPs. The cytotoxicity of the HCA-Fe-Pt NPs was evaluated by incubating cells with different concentrations of Fe-Pt NPs (10, 50, 100, 250 and $550 \mu \mathrm{g}$ Fe-Pt per mL) for $24 \mathrm{~h}$. The cell viabilities obtained after the incubation with NPs for all the tested concentrations are summarized in Table 1.

Even at the highest tested concentration $(550 \mu \mathrm{g}$ Fe-Pt per $\mathrm{mL}$ ), which is much above the concentration level that is usually used in in vitro studies, the cell viability remained high (94.8 \pm $2.1 \%$ ). Comparing these results with the literature data presented in the introduction part it can be seen that the HCAcoated Fe-Pt NPs showed no significant cytotoxicity, even at much higher concentrations than the NPs coated with cysteine ${ }^{34}$ $\left(100 \mu \mathrm{g}\right.$ Fe-Pt per $\mathrm{mL}$ ) or cysteamine ${ }^{\mathbf{1 1}}$ (30 $\mu \mathrm{g}$ Fe-Pt per $\mathrm{mL}$ ), which are the two most commonly used molecules from the studies found in the literature. Because the presence of the NPs may induce a delayed cytotoxic effect, it is important to follow the cell viability of the cells for an extended period of time. 
Table 1 Cell viabilities for the RT4 cells after the incubation with HCA-Fe-Pt NPs with different concentrations for $24 \mathrm{~h}(n=3)$

\begin{tabular}{llllll}
\hline Concentration $(\mu \mathrm{g}$ Fe-Pt per $\mathrm{mL})$ & 0 & 10 & 25 & 50 & 250 \\
\hline Cell viability (\%) & 94.4 & 94.9 & 97.1 & 95.6 & 96.5 \\
Std dev. & \pm 3.4 & \pm 2.3 & \pm 1.5 & \pm 0.5 & \pm 1.1
\end{tabular}

Measurements revealed that 1 day and 7 days after the NPs' removal the cell viabilities remained high $(>95 \%$, data not shown). From this it can be concluded that due to the presence of the HCA-Fe-Pt NPs no delayed cytotoxic effect was observed.

3.3.2 Time-dependent cellular uptake: microscopy and ICP-MS analysis. In order to follow the process of the NPs' internalization and to explain the mechanism of the cellular uptake, RT4 cells were incubated with $100 \mu \mathrm{g} \mathrm{mL}{ }^{-1}$ HCA-Fe-Pt NPs for 1 or $12 \mathrm{~h}$, washed to remove the non-internalized NPs and then fixed or cultured for an additional $24 \mathrm{~h}$. After each time point, the samples were analyzed with TEM to visualize the NPs' location in the cells (Fig. 5). TEM images of the control cells are shown in Fig. 5a. TEM images of the cells incubated with HCA-Fe-Pt NPs for $1 \mathrm{~h}, 12 \mathrm{~h}$ are shown in Fig. 5b and c, respectively, and $24 \mathrm{~h}$ after $12 \mathrm{~h}$ incubation with HCA-Fe-Pt NPs are shown in Fig. 5 d. After $1 \mathrm{~h}$ of the incubation only a few NPs can be found on the cell membrane (plasma membrane) or internalized (Fig. 5b), while after $12 \mathrm{~h}$ the amount of internalized NPs is significantly higher (Fig. 5c). These results revealed a strong time-dependent cellular uptake. The amount of NPs was not significantly changed 24 hours after the 12 h-incubation (Fig. 5d). The NPs were generally no longer on the cell surface; however, they were clearly visible intracellularly in endosomal compartments (Fig. 5d'). Importantly, the cell organelles were, at all time points, well preserved and of normal morphology. Moreover, the NPs were not caught in the intracellular space of the RT4 cell model.
Further TEM analyses enabled us to follow the HCA-Fe-Pt NPs internalization pathway, from the cell surface (Fig. 6a-c) into the cells (Fig. 6d-g). NPs were observed in different endosomal compartments, e.g., based on their ultrastructural characteristics, mainly in early and late endosomes (Fig. 6d-g). Regarding the ultrastructural changes of the apical surface, i.e., prominent ruffling of the plasma membrane and engulfment of small NP aggregates, the most likely endocytotic mechanism would be through macropinocytotis, which enables the nonspecific internalization of larger volumes of a fluid phase with intensive plasma membrane evaginations in the form of blebs, ruffles and lamellar evaginations, also in non-phagocytic cells. ${ }^{35}$ Moreover, we have noticed some clathrin-dependent endocytosis (Fig. 6c). Since it is known that NP internalization depends not only on the physicochemical properties of NPs ${ }^{36}$ the extracellular environment (e.g., $\mathrm{pH}$, ion and protein composition ${ }^{37}$ ), but also on the cell type $\mathrm{e}^{38}$ and their differentiation stage, ${ }^{39,40}$ we must also be aware that the utilized endocytotic pathway for HCA-Fe-Pt NPs could be different in other cell types.

Furthermore, in order to quantitatively assess the NPs' uptake, an ICP-MS analysis was made and the concentration of Fe and Pt in the cells was determined. Cells incubated for $12 \mathrm{~h}$ with a NP concentration of $100 \mu \mathrm{g} \mathrm{m} \mathrm{m}^{-1}$ were used in these experiments. Because the cells already naturally contain $\mathrm{Fe}$, samples that were not exposed to the NPs and the cell culture medium were measured as the control samples. No Pt was expected to be present in the control samples. Furthermore, to follow the fate of the NPs for an extended period of time, 1 day
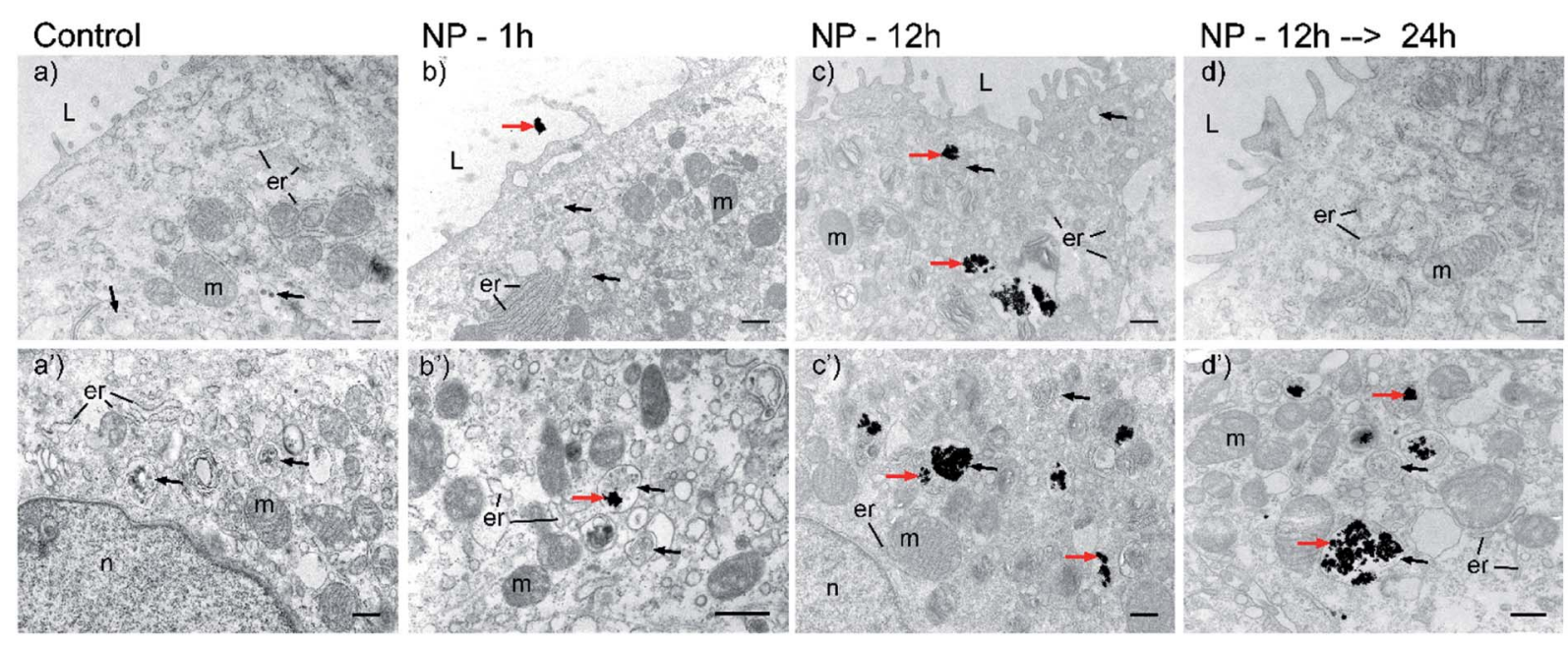

Fig. 5 Transmission electron microscopy images of RT4 cells during incubation with HCA-Fe-Pt NPs. Panels a-d show the cell surface and apical region of the cells, while $a^{\prime}-d^{\prime}$ show the central cytoplasm. ( $a$ and $\left.a^{\prime}\right)$ Control cells before incubation, (b and b') cells after $1 \mathrm{~h}$ of incubation, (c and $\left.c^{\prime}\right)$ cells after $12 \mathrm{~h}$ of incubation and ( $\mathrm{d}$ and $\mathrm{d}^{\prime}$ ) after the $12 \mathrm{~h}$ period of incubation with NPs, followed by $24 \mathrm{~h}$ incubation without NPs. Legend: red arrows - HCA-Fe-Pt NPs, black arrows - endosomal compartments, er - endoplasmic reticulum, $\mathrm{L}$ - lumen, $\mathrm{m}$ - mitochondria, $\mathrm{n}$ - nucleus. Bar: $500 \mathrm{~nm}$. 



Fig. 6 Internalization pathway of HCA-Fe-Pt NPs into the RT4 cells. (a) RT4 cell exposed to NPs. NPs were detected in the lumen (green arrows) and associated with the cell apical plasma membrane, where they formed bigger (b) and smaller (c and d) clusters of NPs. Apical plasma membrane around the NP started to evaginate and then invaginate into the cell's cytoplasm (black arrows), presumably by the mechanism of (b) macropinocytosis and (c) clathrin-dependent endocytotis. (d) Beneath the apical plasma membrane, internalized NPs were seen in early endosomes (ee), which progressively matured into the late endosomes (le; e-g). During endosome maturation, NPs in them accumulated and were mixed with the other cell membranes and components, determined for degradation $(\mathrm{e}-\mathrm{g})$. Legend: green arrows - HCA-Fe-Pt NPs in the lumen, red arrows - endocytosed HCA-Fe-Pt NPs, black arrows - invagination of the apical plasma membrane, ee - early endosome, er endoplasmic reticulum, ga - Golgi apparatus, le - late endosome, $\mathrm{m}$ - mitochondria, mvb - multivesicular body, $\mathrm{n}$ - nucleus. Bars: (a) 2 $\mu \mathrm{m}$, (bg) $200 \mathrm{~nm}$.

and 7 days after the removal of the NPs, an ICP-MS analysis was made and the calculated concentrations of Fe and Pt in the cells are shown in Table 2 .

The concentration of Fe in the samples was found to be 1.44, 1.70 and $1.54 \mu \mathrm{g} \mathrm{mL} \mathrm{m}^{-1}$ immediately after the incubation, 24 hours and 1 week after incubation, respectively. On average, the Fe concentration in the cells was found to be $1.56 \mu \mathrm{g}$ Fe per $\mathrm{mL}$. Moreover, in the case of the Fe concentration, naturally occurring Fe in the cells $\left(0.41 \pm 0.03 \mu \mathrm{g} \mathrm{mL}^{-1}\right)$ has to be subtracted to obtain the Fe concentration only due to the presence of the FePt NPs. The normalized values for $\mathrm{Fe}$ are shown in Table 2 (labelled as $\mathrm{Fe}_{\text {norm. }}$.). The concentration of $\mathrm{Pt}$ in the samples was found to be $19.7,22.1$ and $20.3 \mu \mathrm{g} \mathrm{mL} \mathrm{m}^{-1}$ immediately after incubation, 24 hours and 1 week after incubation, respectively.

Table 2 Fe and Pt concentrations determined with ICP analysis on the samples 0 h, 1 day and 7 days after the NPs' removal (incubation time was $12 \mathrm{~h}$ with concentration of HCA-Fe-Pt NPs $100 \mu \mathrm{g} \mathrm{mL}^{-1}$ )

\begin{tabular}{lll}
\hline & Fe $\mu g$ per $\mathrm{mL}$ & Pt $\mu$ g per $\mathrm{mL}$ \\
\hline Cell culture medium & $0.20 \pm 0.03$ & $<0.0001$ \\
Cells & $0.41 \pm 0.03$ & $0.003 \pm 0.003$ \\
Cells + NPs (0 h) & $1.44 \pm 0.06$ & $19.7 \pm 1.5$ \\
Cells + NPs (1 day) & $1.70 \pm 0.11$ & $22.1 \pm 1.7$ \\
Cells + NPs (7 days) & $1.54 \pm 0.09$ & $20.3 \pm 1.9$ \\
Average & $1.56 \pm 0.11$ & $20.7 \pm 1.0$ \\
Normalized & $1.14\left(\mathrm{Fe}_{\text {norm. }}\right)$ & $20.7\left(\mathrm{Pt}_{\text {norm. }}\right)$ \\
Sum (Fe + Pt) & $21.8 \mu \mathrm{gmL}^{-1}$ & \\
Initial suspension & $100 \mu \mathrm{g} \mathrm{mL}^{-1}$ & \\
Uptake (\%) & $21.8 \%$ &
\end{tabular}

On average, the cellular uptake was found to be $20.7 \mu \mathrm{g}$ Pt per $\mathrm{mL}$. Because the concentrations of $\mathrm{Fe}$ and Pt are not decreasing with time this indicates that the NPs remain internalized and are not excreted by the cells. The total amount of Fe and Pt in the sample incubated for $12 \mathrm{~h}$ with Fe-Pt NPs was found to be $21.8 \mu \mathrm{g} \mathrm{mL}^{-1}$. By dividing this value by the initial concentration of the NP suspension that was used in the experiment $(100 \mu \mathrm{g}$ $\mathrm{mL}^{-1}$ ), the cellular uptake was calculated to be $21.8 \%$. In order to gain a better insight into the cellular uptake, the concentrations of Fe and Pt are expressed per one cell. Therefore, the Fe and $\mathrm{Pt}$ concentrations were divided by the total mass of the cells in the sample (number of cells in the sample $\times$ mass of one cell). Using this approach, the concentrations of $0.33 \mathrm{pg}$ Fe per cell and 6.31 pg Pt per cell were calculated. The high cellular uptake determined using the ICP-MS analysis is in a good agreement with the data obtained with the electron microscopy, where the images showed a significant amount of NPs internalized by the cells.

3.3.3 In vitro NMR relaxivities. The $T_{1}$ and $T_{2}$ relaxation times for the cells that were incubated with different concentrations of HCA-Fe-Pt NPs $\left(0,10,50\right.$ and $100 \mu \mathrm{g} \mathrm{mL}^{-1}$ for $\left.12 \mathrm{~h}\right)$ were measured and the results are listed in Table 3 . The $T_{1}(0)$ and $T_{2}(0)$ values represent the $0 \mathrm{mM}$ concentration, i.e., control cells that were not incubated with NPs. In order to assess the decrease of the $T_{1}$ or $T_{2}$ value due to the presence of the hybrid NPs, the ratios $T_{1} / T_{1}(0)$ and $T_{2} / T_{2}(0)$ between each sample and the control sample were calculated. From the calculations in Table 3 it is clear that the incubation of the cells with Fe-Pt NPs 
Table 3 List of $T_{1}$ and $T_{2}$ relaxation times obtained in vitro experiments for the cells that were incubated with different concentrations of HCAFe-Pt NPs $\left(0,10,50\right.$ and $\left.100 \mu \mathrm{g} \mathrm{mL}{ }^{-1}\right)$ with the corresponding calculated $T_{1} / T_{1}(0)$ and $T_{2} / T_{2}(0)$ ratios. For comparison, the values for pure water $(T(0)-$ aq) and the aqueous suspension of Fe-Pt NPs (T(Fe-Pt)-aq) are added

\begin{tabular}{|c|c|c|c|c|c|}
\hline Samples & Fe conc. $(\mu \mathrm{g} \mathrm{mL})$ & $T_{1}(\mathrm{~ms})$ & Ratio $T_{1} / T_{1}(0)$ & $T_{2}(\mathrm{~ms})$ & Ratio $T_{2} / T_{2}(0)$ \\
\hline$T(0)$-cells & 0 & $2340 \pm 40$ & 1 & $210 \pm 10$ & 1 \\
\hline$T(10)$-cells & N/A & $2300 \pm 40$ & 0.98 & $63 \pm 3$ & 0.30 \\
\hline$T(50)$-cells & N/A & $1690 \pm 30$ & 0.72 & $32 \pm 2$ & 0.15 \\
\hline$T(100)$-cells & 1.14 & $1660 \pm 30$ & 0.71 & $36 \pm 2$ & 0.17 \\
\hline$T(0)-\mathrm{aq}$ & 0 & $3089 \pm 42$ & 1 & $2077 \pm 2$ & 1 \\
\hline$T(\mathrm{Fe}-\mathrm{Pt})-\mathrm{aq}$ & 1.40 & $2206 \pm 23$ & 0.71 & $364 \pm 2$ & 0.18 \\
\hline
\end{tabular}

having different concentrations $\left(10,50\right.$ and $\left.100 \mu \mathrm{g} \mathrm{mL} \mathrm{m}^{-1}\right)$ the $T_{1}$ relaxation time decreased to 98,72 and $71 \%$ of the initial $T_{1}(0)$ value due to the NPs' uptake. Furthermore, in the case of the $T_{2}$ relaxation-time measurements it can be seen that the $T_{2}$ values are decreased significantly to 30,15 and $17 \%$ of the initial $T_{2}(0)$ value for the concentrations of Fe-Pt NPs of 10, 50 and $100 \mu \mathrm{g}$ $\mathrm{mL}^{-1}$, respectively. Due to the superparamagnetic nature of the NPs, Fe-Pt NPs have a more significant effect on the shortening of $T_{2}$ than the $T_{1}$ relaxation time. The same behaviour was observed in ex vitro experiments measuring aqueous suspensions of $\mathrm{Fe}-\mathrm{Pt}$ NPs. ${ }^{6}$ It seems that at higher incubation concentrations (50 and $100 \mu \mathrm{g} \mathrm{mL}^{-1}$ ) the saturation is achieved and the $T_{2}$ values stabilized around $16 \%$ of the initial $T_{2}(0)$. It can be seen that the exposure of the cells to the lowest used concentration of NPs $\left(10 \mu \mathrm{g} \mathrm{mL} \mathrm{m}^{-1}\right)$ is enough to decrease the $T_{2}$ value by $70 \%$. In terms of the MRI imaging this means a large improvement in the contrast, even for low NP concentrations and easier visualization of the tissues containing NPs, proving that HCA-Fe-Pt NPs have great potential to be used as MRI contrast agents.

Up to now, only one report could be found where in vitro MRI experiments were performed using Fe-Pt NPs. ${ }^{14}$ More precisely, HeLa cells were incubated with tetraethylene glycol/oleic acidcoated $4 \mathrm{~nm}$-large $\mathrm{Fe}-\mathrm{Pt}$ nanoparticles and the $r_{2}$ was calculated to be $68.7 \mathrm{mM}^{-1} \mathrm{~s}^{-1}$, which is lower than in an aqueous environment $\left(r_{2}=122 \mathrm{mM}^{-1} \mathrm{~s}^{-1}\right)$. Unfortunately, no explanation for this drop in the $r_{2}$ value was given. Shortening the relaxation time depends on several parameters, such as the NPs' size and concentration, water accessibility and the distribution of NPs within the micro-environment. ${ }^{41}$ In suspensions the NPs are free to move and have easier access to the water protons. While in cells the NPs are usually trapped in the intracellular compartments and, therefore, their influence on the water protons could be weaker. ${ }^{41}$ Therefore, in order to assess the behaviour of the Fe-Pt NPs in a different environment, a comparison of the $T_{1}$ and $T_{2}$ relaxation times obtained for the $\mathrm{Fe}-\mathrm{Pt}$ NPs in the water suspension and the Fe-Pt NPs internalized in the cells was performed. Iron, as the magnetic atom in the NPs, is responsible for the generation of the magnetic field, which influences the $T_{2}$ relaxation time of the water protons; therefore, samples with the same Fe content were compared. For the cells incubated with the Fe-Pt suspension having a concentration of $100 \mu \mathrm{g} \mathrm{mL} \mathrm{m}^{-1}$, the Fe content in the cells was determined to be $1.14 \mu \mathrm{g} \mathrm{mL}^{-1}$ (Table 2). For comparison purposes, the $T_{1}$ and $T_{2}$ relaxation times for the aqueous suspension with the same Fe content were taken from our previous study ${ }^{6}$ and are listed in Table 3 , where $T(0)$-aq stands for the pure water and $T(\mathrm{Fe}-\mathrm{Pt})$-aq for the $\mathrm{Fe}-\mathrm{Pt}$ suspension with an iron concentration of $1.40 \mu \mathrm{g} \mathrm{mL}$. Calculations revealed that the $T_{1} / T_{1}(0)$ and $T_{2} / T_{2}(0)$ ratios for both samples, i.e., the cell pellet and the aqueous suspension, having similar Fe contents, are comparable. This indicates that the Fe-Pt NPs in the cellular environment have a similar effect on the shortening of the $T_{1}$ and $T_{2}$ relaxation times as in the suspension. However, to determine the effect of the environment more precisely (water suspension $v s$. intracellular position) more detailed experiments with a larger population of the samples over a wider concentration range have to be performed. Relaxivity coefficients $\left(r_{2}\right.$ or $\left.r_{1}, \mathrm{mM}^{-1} \mathrm{~s}^{-1}\right)$ are important parameters that define the ability to accelerate the relaxation rates $\left(R_{2}\right.$ or $\left.R_{1}, \mathrm{~s}^{-1}\right)$. In our previous study, ${ }^{6}$ relaxivity values for Fe-Pt clusters in an aqueous suspension were calculated to be $r_{1}$ $=6.7 \pm 0.7 \mathrm{mM}^{-1} \mathrm{~s}^{-1}$ and $r_{2}=87 \pm 4 \mathrm{mM}^{-1} \mathrm{~s}^{-1}$ with an $r_{2} / r_{1}$ ratio 12.9, which put Fe-Pt nanoparticles high on the list of the most promising materials for use in MRI. We are aware that our $r_{2}$ values for the Fe-Pt nanoparticles are, however, still inferior to iron oxides clusters, mainly due to their higher $m_{\mathrm{s}}{ }^{42-45} \mathrm{But}$, despite their good magnetic properties, the Fe-oxide nanoparticles were found to have a limited trans-endothelia passage and tissue penetration, since they suffer from rapid clearance by phagocytic cells, ${ }^{46,47}$ which could be limiting in terms of their biomedical implementations. The MRI performance of the FePt NPs can be further improved with a careful preparation of NPs with the maximum $m_{\mathrm{s}}$ that can be achieved for this material in the superparamagnetic range. An important step towards the realization of this goal was achieved in the scope of this study, where the guidelines for the optimal NP size and morphology were given. Additionally, the surface layer can be optimized in the future in order to increase the $r_{2}$. However, the biocompatibility of the selected ligand has to be taken into account to ensure the NPs' safety as well. Therefore, the development of new, biocompatible ligands, such as HCA, is of vital importance for the successful implementation of nanoparticulate systems to be used as safe and efficient MRI contrast agents.

\section{Conclusions}

Separated Fe-Pt NPs and Fe-Pt clusters were synthesized and the magnetic interactions were studied to obtain the optimal size and morphology that would lead to the highest possible $m_{\mathrm{s}}$ 
in the superparamagnetic regime. This was obtained by combining the NPs just below the $D_{\mathrm{SPL}}$, into clusters as a consequence of the exchange interactions acting between the individual Fe-Pt particles. Excellent stability of Fe-Pt NPs was achieved with a successful ligand exchange using a novel HCA ligand, the binding of which to the Fe-Pt NPs was proved via a FTIR study. The in vitro study made on HCA-functionalized Fe-Pt clusters revealed that the as-prepared NPs are not cytotoxic to the urothelial RT4 cell line, even at the highest used concentration $\left(550 \mu \mathrm{g} \mathrm{mL} \mathrm{m}^{-1}\right.$ of Fe-Pt NPs) that surpasses the concentrations used in the literature so far. Furthermore, no delayed cytotoxic effect was observed even 1 week after the cells' exposure to the NPs. A TEM analysis revealed a time-dependent cellular uptake. After $1 \mathrm{~h}$ of the incubation only a few NPs can be found on the cell membrane or internalized, while after $12 \mathrm{~h}$ the amount of internalized NPs is significantly higher and clearly visible intracellularly in the endosomal compartments. Despite the presence of the NPs, the cell organelles were found to be well preserved and of normal morphology, which further indicates the biocompatibility of HCA-Fe-Pt NPs. Moreover, an ICPMS analysis was used to quantitatively assess the amount of NPs taken up. The results were in good agreement with the TEM observations. Finally, in vitro MRI measurements have shown that the exposure of the cells to the lowest used concentration of the HCA-Fe-Pt NPs $\left(10 \mu \mathrm{g} \mathrm{mL}{ }^{-1}\right)$ is already enough to decrease the $T_{2}$ value by $70 \%$. Thus proving that HCA-Fe-Pt NPs have great potential for use as efficient and safe MRI contrast agents.

\section{Conflicts of interest}

There are no conflicts to declare.

\section{Acknowledgements}

We thank Irena Abramovič, Sanja Čabraja and Sabina Železnik for their technical support. The study was supported by the Slovenian Research Agency ARRS (project numbers P3-0108 and J2-6760).

\section{Notes and references}

1 S. Chen and P. Andre, Int. J. Nanotechnol., 2012, 9, 39.

2 S. Maenosono and S. Saita, IEEE Trans. Magn., 2006, 42, 1638-1642.

3 X. W. Wu, C. Liu, L. Li, P. Jones, R. W. Chantrell and D. Weller, J. Appl. Phys., 2004, 95, 6810-6812.

4 S. Sun, Science, 2000, 287, 1989-1992.

5 N. T. K. Thanh, Magnetic Nanoparticles: From Fabrication to Clinical Applications, CRC Press, Taylor \& Francis, London, 2012.

6 N. Kostevšek, S. Šturm, I. Serša, A. Sepe, M. Bloemen, T. Verbiest, S. Kobe and K. Žužek Rožman, J. Nanopart. Res., 2015, 17, 464.

7 L. a. W. Green, T. T. Thuy, D. M. Mott, S. Maenosono and N. T. Kim Thanh, RSC Adv., 2014, 4, 1039.

8 J. Gao, G. Liang, B. Zhang, Y. Kuang, X. Zhang and B. Xu, J. Am. Chem. Soc., 2007, 129, 1428-1433.
9 S. Liang, Q. Zhou, M. Wang, Y. Zhu, Q. Wu and X. Yang, Int. J. Nanomed., 2015, 10, 2325-2333.

10 H. Sun, X. Chen, D. Chen, M. Dong, X. Fu, Q. Li, X. Liu, Q. Wu, T. Qiu, T. Wan and S. Li, Int. J. Nanomed., 2012, 7, 3295-3307.

11 S. Chen, L. Wang, S. L. Duce, S. Brown, S. Lee, A. Melzer, S. A. Cuschieri and P. André, J. Am. Chem. Soc., 2010, 132, 15022-15029.

12 S. W. Chou, Y. H. Shau, P. C. Wu, Y. S. Yang, D. Bin Shieh and C. C. Chen, J. Am. Chem. Soc., 2010, 132, 13270-13278.

13 Z. Bao, M. He, H. Quan, D. Jiang, Y. Zheng, W. Qin, Y. Zhou, F. Ren, M. Guo and C. Jiang, RSC Adv., 2016, 6, 35124-35134.

14 H. Yang, J. Zhang, Q. Tian, H. Hu, Y. Fang, H. Wu and S. Yang, J. Magn. Magn. Mater., 2010, 322, 973-977.

15 Y. Liu, K. Yang, L. Cheng, J. Zhu, X. Ma, H. Xu, Y. Li, L. Guo, H. Gu and Z. Liu, Nanomedicine, 2013, 9, 1077-1088.

16 C. Xu, Z. Yuan, N. Kohler, J. Kim, M. A. Chung and S. Sun, J. Am. Chem. Soc., 2009, 131, 15346-15351.

17 N. K. Sahu, J. Gupta, D. Bahadur, F.-P. Gao, Y.-S. Fan, X.-J. Li, Z.-Y. Duan, H. Wang, G. D. Stucky, B. Ratner and M. Zhang, Dalton Trans., 2015, 44, 9103-9113.

18 Y. Liu, T. Chen, C. Wu, L. Qiu, R. Hu, J. Li, S. Cansiz, L. Zhang, C. Cui, G. Zhu, M. You, T. Zhang and W. Tan, J. Am. Chem. Soc., 2014, 16-19.

19 C. Xu, K. Xu, H. Gu, R. Zheng, H. Liu, X. Zhang, Z. Guo and B. Xu, J. Am. Chem. Soc., 2004, 126, 9938-9939.

20 M. Nardini, M. D'Aquino, G. Tomassi, V. Gentili, M. Di Felice and C. Scaccini, Free Radicals Biol. Med., 1995, 19, 541-552.

21 T. Togashi, S. Takami, K. Kawakami, H. Yamamoto, T. Naka, K. Sato, K. Abe and T. Adschiri, J. Mater. Chem., 2012, 22, 9041.

22 M. E. Kreft, S. Hudoklin and M. Sterle, Folia Biol., 2005, 51, 126-132.

23 S. Saita and S. Maenosono, Chem. Mater., 2005, 17, 66246634.

24 M. S. Seehra, V. Singh, P. Dutta, S. Neeleshwar, Y. Y. Chen, C. L. Chen, S. W. Chou and C. C. Chen, J. Phys. D: Appl. Phys., 2010, 43, 145002.

25 S. Bedanta and W. Kleemann, J. Phys. D: Appl. Phys., 2009, 42, 13001.

26 L. Lartigue, P. Hugounenq, D. Alloyeau, S. P. Clarke, M. Lévy, J. C. Bacri, R. Bazzi, D. F. Brougham, C. Wilhelm and F. Gazeau, ACS Nano, 2012, 6, 10935-10949.

27 F. Ahrentorp, A. Astalan, J. Blomgren, C. Jonasson, E. Wetterskog, P. Svedlindh, A. Lak, F. Ludwig, L. J. van IJzendoorn, F. Westphal, C. Grüttner, N. Gehrke, S. Gustafsson, E. Olsson and C. Johansson, J. Magn. Magn. Mater., 2015, 380, 221-226.

28 V. Schaller, G. Wahnström, A. Sanz-Velasco, S. Gustafsson, E. Olsson, P. Enoksson and C. Johansson, Phys. Rev. B: Condens. Matter Mater. Phys., 2009, 80, 1-4.

29 N. Shukla, C. Liu, P. M. Jones and D. Weller, J. Magn. Magn. Mater., 2003, 266, 178-184.

30 X. Gao, D. W. Metge, C. Ray, R. W. Harvey and J. Chorover, Environ. Sci. Technol., 2009, 43, 7423-7429.

31 Y. S. Hwang, J. Liu, J. J. Lenhart and C. M. Hadad, J. Colloid Interface Sci., 2007, 307, 124-134. 
32 T. Rajh, L. X. Chen, K. Lukas, T. Liu, M. C. Thurnauer and D. M. Tiede, J. Phys. Chem. B, 2002, 106, 10543-10552.

33 T. Togashi, T. Naka, S. Asahina, K. Sato, S. Takami and T. Adschiri, Dalton Trans., 2011, 40, 1073-1078.

34 S. Liang, Q. Zhou, M. Wang, Y. Zhu, Q. Wu and X. Yang, Int. J. Nanomed., 2015, 10, 2325-2333.

35 J. P. Lim and P. A. Gleeson, Immunol. Cell Biol., 2011, 89, 836-843.

36 B. Fadeel, A. Fornara, M. S. Toprak and K. Bhattacharya, Biochem. Biophys. Res. Commun., 2015, 468, 498-503.

37 C. Petters, F. Bulcke, K. Thiel, U. Bickmeyer and R. Dringen, Neurochem. Res., 2014, 39, 372-383.

38 F. Joris, B. B. Manshian, K. Peynshaert, S. C. De Smedt, K. Braeckmans and S. J. Soenen, Chem. Soc. Rev., 2013, 42, 8339.

39 J. Lojk, V. B. Bregar, K. Strojan, S. Hudoklin, P. Veranič, M. Pavlin and M. E. Kreft, Histochem. Cell Biol., 2018, 149, 45-59.
40 S. Hudoklin, D. Zupančič, D. Makovec, M. E. Kreft and R. Romih, Int. J. Nanomed., 2013, 8, 3945.

41 O. M. Girard, R. Ramirez, S. McCarty and R. F. Mattrey, Contrast Media Mol. Imaging, 2012, 7, 411-417.

42 K. Tanaka, A. Narita, N. Kitamura, W. Uchiyama, M. Morita, T. Inubushi and Y. Chujo, Langmuir, 2010, 26, 11759-11762.

43 H. Chen, J. Yeh, L. Wang, H. Khurshid, N. Peng, A. Y. Wang and H. Mao, Nano Res., 2010, 3, 852-862.

44 J.-F. Berret, N. Schonbeck, F. Gazeau, D. El Kharrat, O. Sandre, A. Vacher and M. Airiau, J. Am. Chem. Soc., 2006, 128, 1755-1761.

45 H. Ai, C. Flask, B. Weinberg, X. Shuai, M. D. Pagel, D. Farrell, J. Duerk and J. Gao, Adv. Mater., 2005, 17, 1949-1952.

46 H. Bin Na, I. C. Song and T. Hyeon, Adv. Mater., 2009, 21, 2133-2148.

47 J. W. M. Bulte and D. L. Kraitchman, NMR Biomed., 2004, 17, 484-499. 